This item was submitted to Loughborough's Research Repository by the author.

Items in Figshare are protected by copyright, with all rights reserved, unless otherwise indicated.

\title{
The effect of downside risk reduction on UK equity portfolios included with
}

\section{Managed Futures Funds}

PLEASE CITE THE PUBLISHED VERSION

http://dx.doi.org/10.1016/j.irfa.2009.09.007

PUBLISHER

(C) Elsevier

VERSION

SMUR (Submitted Manuscript Under Review)

LICENCE

CC BY-NC-ND 4.0

\section{REPOSITORY RECORD}

Tee, Kai-Hong. 2019. "The Effect of Downside Risk Reduction on UK Equity Portfolios Included with Managed Futures Funds". figshare. https://hdl.handle.net/2134/14794. 
This item was submitted to Loughborough's Institutional Repository (https://dspace.lboro.ac.uk/) by the author and is made available under the following Creative Commons Licence conditions.

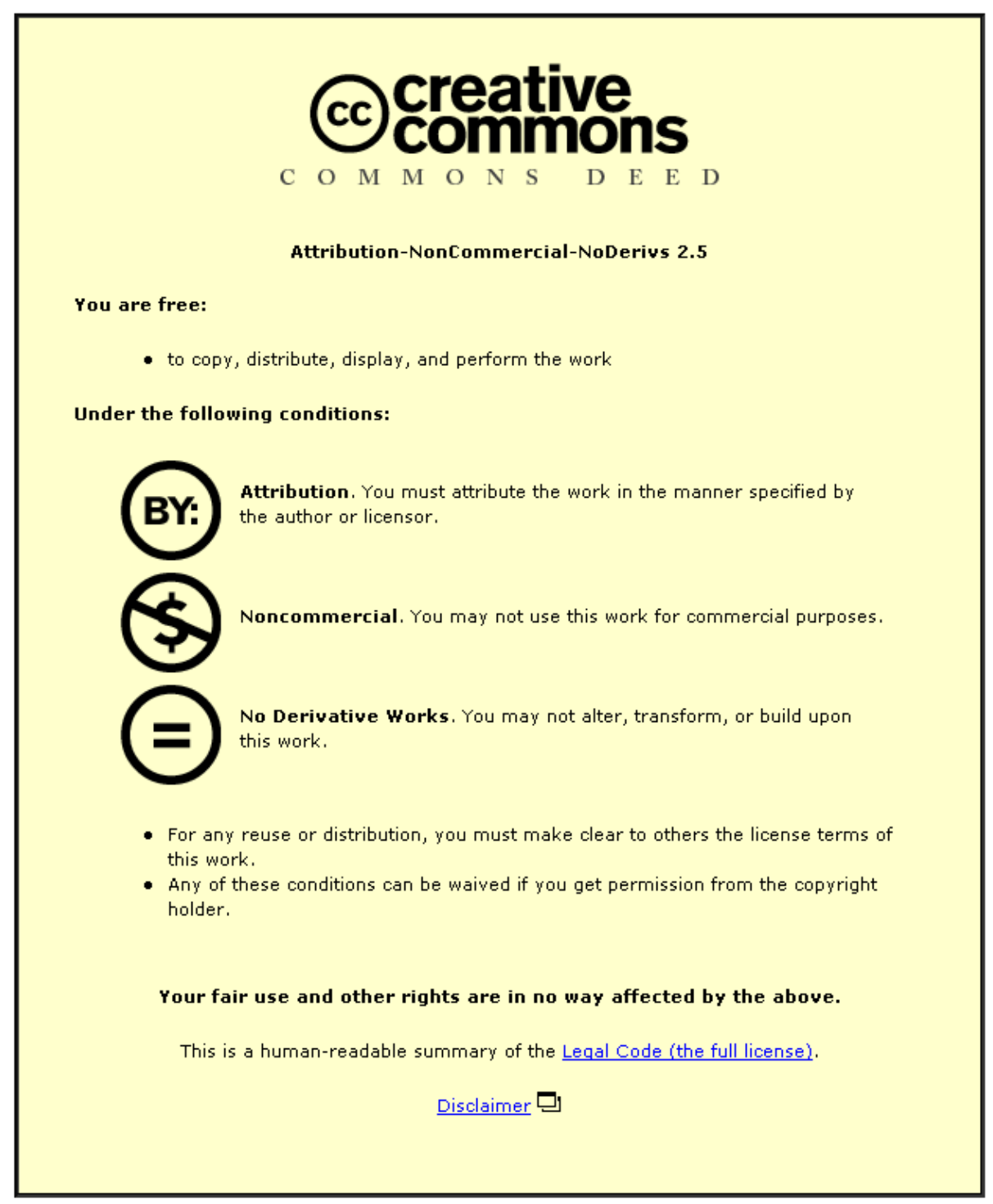

For the full text of this licence, please go to: http://creativecommons.org/licenses/by-nc-nd/2.5/ 


\title{
The effect of Downside Risk Reduction
}

\section{On UK Investment Portfolios}

\author{
Kai-Hong Tee
}

\begin{abstract}
This paper investigates the effect of downside risk reduction on UK investment portfolios. We compare the UK equity portfolio (containing Managed Futures) performance outcomes arising from using the n-degree Lower Partial Moment (LPM) and the Minimum Variance asset allocation models. We find that, through the use of the n-degree LPM models, assets can be allocated more effectively based on their below-target variations or downside risks for the portfolio. This resulted in a better out-sample portfolio returns than the minimum variance model. It, however, introduced positive skewness to the portfolio and results suggest that as skewness increases beyond quite modest limits both diversification and portfolio returns tend to deteriorate. Our findings about this relationship pattern are similar to the academic literatures. This paper highlighted the importance of proper understanding one's risk tolerance in investment decision making, especially downside risk, which we reveal it could often affect portfolio returns badly.
\end{abstract}

Keywords: Downside Risk, Lower Partial Moment, skewness, Diversification JEL Classification numbers: G15 G11 


\section{The effect of Downside Risk Reduction}

\section{On UK Investment Portfolios}

\section{Introduction}

There is a recent interest in the academic literature on the discussions of Lower Partial Moment (thereafter, LPM), due to the prominence of the use of Valueat-risk $^{1}$ (thereafter, VaR). For example, research in Danielsson et al (2006) and Hyung and de Vries (2005) had related VaR to lower partial moments. The development of LPM can be traced back in the academic literatures to as early as in the 1950's. In discussing LPM, these authors, however, tend not to focus on the fact that LPM can flexibly capture varying degrees of risk tolerance and their implications in a portfolio allocation problem. This paper aims to review and discuss the risk measures related to LPM, its development and how VaR is related to it. By conducting an empirical study that stands from the UK's perspective, this paper shows, how LPM can be used to demonstrate the effect of downside risk reduction on portfolio returns and diversifications. Section two of the paper reviews the literature dealing with the rationale, structure and development of the LPM model. Section three discusses the empirical objective of the analysis, the data used and research method used in this paper. Section four presents and discusses the main findings, and section five summarises the findings and discusses implications of the analysis.

\footnotetext{
${ }^{1}$ Readers keen to know more about Value-at-Risk may consult Jorion (2002) for more details
} 


\section{$2 \quad$ Literature Review}

\subsection{Risk Measures of Variance and Below-Target Variance}

Since the publication of Markowitz's (1959) seminal paper on portfolio diversification, there have been numerous subsequent studies on portfolio selection and performance, the overwhelming majority of which have focused exclusively upon the first two moments of return distributions: the mean and variance.

The idea of downside risk emerged in Markowitz (1959) when he recognised that analyses based on variance assume that investors are equally anxious to eliminate both extremes of the return distribution. Markowitz (1959) suggested that this did not accurately reflect investor preferences for minimising possible losses and that, therefore, analyses based on the semi variance, which assumes that investors' primary decision criterion is on reducing losses below target mean returns, could provide a more accurate model of investor decision making. By concentrating on minimising portfolio losses below target mean returns, this type of analysis produces portfolio allocations that minimise the probability of below target means returns ${ }^{2}$.

According to Nawrocki (1999), Markowitz (1959) provides two suggestions for measuring downside risk: a semi-variance computed from the mean return or below-mean semi variance $(S V m)$ (shown by equation (1) as follows) and a semi variance computed from a target return or below-target semi variance (SVt) (shown by

\footnotetext{
${ }^{2}$ However, due to the complexity and the costs involved in the computation of semi-variance analyses, Markowitz (1959) chose not to pursue this line of inquiry. He rejected the semi-variance as the referred risk measure and concentrated instead on his now famous mean-variance approach to portfolio theory. Even so, Markowitz (1959,
} 
equation (2) as follows). The two measures compute variance using the returns below the mean return $(S V m)$ or below a target return $(S V t)$. Since only a subset of the return distribution is used, Markowitz called them partial or semi-variances.

$$
\begin{array}{ll}
S V_{m}=\frac{1}{k} \sum_{i=1}^{k}\left[\operatorname{Max}\left(0,\left(E-R_{T}\right)\right]^{2}\right. & \text { below-mean semi variance } \\
S V_{t}=\frac{1}{k} \sum_{i=1}^{k}\left[\operatorname{Max}\left(0,\left(t-R_{T}\right)\right]^{2}\right. & \text { below-target semi variance }
\end{array}
$$

$R_{T}$ is the asset return during time period $T, K$ is the number of observations, $\mathrm{t}$ is the target rate of return and $E$ is the expected mean return of the asset's return. Max indicates that the formula will square the greater of the two values, 0 , or $\left(t-R_{T}\right)$.

Nawrocki (1999) and Harlow (1991) discussed the development and research of both below target and below means semi-variances and found one of the most enduring and related ideas involves focusing on the tail of the relevant distribution of returns, i.e., the returns below some specific threshold level or target rate. Risk measures of this type are referred to as "Lower Partial Moments" (LPM) because only the left-hand tail (i.e., probability of under-achieving a threshold return) of the return distribution is used in calculating risk. LPM may sometimes reveal the extent ${ }^{3}$ of skewness, but it cannot be identified as the "third moment" (skewness) since Skewness ${ }^{4}$ assumes variance as a risk measure while LPM assumes variation of below-target return as risk measure.

pg 194) commented that the superiority of variance with respect to computational and other costs, convenience and familiarity do not, and may not in the future, preclude the use of semi-variance.

${ }^{3}$ Skewness measures the concentration of returns distributions surrounding the mean values. Lower Partial Moment (LPM), however, measures the deviations of returns below a certain target rate, which not necessarily has to be the mean values.

${ }^{4}$ To explain their differences, consider portfolio selection as an example. We assumed a portfolio selection problem with skewness that adopt the Polynomial Goal programming (PGP) method for optimisation, see Lai (1991), Chunhachinda, et al (1997) and Prakash, et al (2003) for more details. In constructing the optimisation, the 


\subsection{Lower Partial Moment and the relation to Value-at-risk}

Nawrocki (1999) observed that the research and subsequent development of downside risk measures and Lower Partial Moment (LPM) progressed greatly following the published work of Bawa (1975) and Fishburn (1977). The LPM describes below-target risk in terms of risk tolerance. Given an investor risk tolerance value $\mathrm{n}$, the general measure, the lower partial moment, is defined as follows.

$$
\operatorname{LPM}(n, t)=\frac{1}{k} \sum_{i=1}^{k}\left[\operatorname{Max}\left(0,\left(t-R_{T}\right)\right]^{n}\right.
$$

Where $K$ is the number of observations, $\mathrm{t}$ is the target return ${ }^{5}, R_{T}$ is the return for the asset during time period $T$ and $n$ is the degree of the lower partial moment. It is the " $n$ " value that differentiates the LPM from the Semi-variance models (in equation (1) and (2)), which restricted $n$ only equal to 2 . The value of $n$ is viewed as the "weights" that placed on the tolerance for the below-target variation. The higher the " $n$ " values, the more investor is risk-averse below the target returns

Equation (3) implies that investors are not likely to be risk averse throughout the possible range of the return distribution and will exhibit risk-averse behaviour or be risk neutral in special situations. The Lower Partial Moment model of equation (3)

\footnotetext{
standard statistical moment of distributions, where investors exhibit a preference for higher values of odd moments (mean return, skewness) and a dislike for higher values of the even moments (variance, kurtosis) (see Scott and Horvath 1980), are considered. Here, multiple objectives related to the three moments are defined, i.e., to maximize expected rate of return, minimize variance and maximize skewness and solved by PGF. Unlike the LPM method, the optimisation algorithm of PGP does not consider the left-hand tail (i.e., left to some threshold level) of the return distribution. The optimisation solved the portfolio selection problem (with skewness) assuming variance as a risk measure. In this case, skewness, together with the other two moments, is used to reflect the attitude towards both the upper and the lower part of the distribution. In the of LPM portfolio selection, the assumption, however, is about minimising the variation of the assets' return below target level, which is the risk measure.

${ }^{5}$ The target value is normally assumed to be "zero". Depending on how target rate is to be defined, alternatively, risk free rate can also be used as target return.
} 
does not capture investor's preference on the derivation above the target rate returns. It assumes investors are assumed to be risk neutral for any returns above the target rate. This means that investors are indifferent with the ranges of returns, as long as they are above the target rate. For the below target returns, investors are showing risk averse behaviour, in which they are keen on minimising the deviation between the actual and the target rate of returns. The utility function underlying the lower partial moment model therefore assumes an asymmetric pattern that differs between below the target and above the target rate returns. Fishburn (1977) gives the details.

Bawa (1975) defined "Lower Partial Moment" as a general family of belowtarget risk measures. One of them is the below-target mean semi-variance, that was discussed in Markowitz (1959) shown by equation (1), in which Fishburn (1977) regards as a special case. Fishburn (1977) also argued that the flexible n-degree Lower Partial Moment allow different values of " $n$ " to be approximated, which implied a wide variety of attitudes, towards risks of falling below a certain target level of returns. According to Fishburn (1977), $\mathrm{n}<1$ is when investors seek for additional risk to a portfolio; $\mathrm{n}>1$ is where the investor is risk averse at the below target returns. Fishburn (1977) and Nawrocki (1992) argue that the Lower Partial Moment algorithm is general enough for it to be tailored to the utility function of an investor. Conceptually at least, an n-degree Lower Partial Moment algorithm in shown by equation (3) should give good scope for stochastic dominance analysis as it represents a general utility function. Furthermore, there are also no restrictive assumptions about the probability distribution of security rates of return ${ }^{6}$.

\footnotetext{
${ }^{6}$ This means that the probability distribution of security returns is relatively irrelevant and has insignificant impact in this case. This is because, despite the distributional characteristics of the security returns, they will all be transformed to capture the upside and downside returns by using equation (3) before being used in the LPM models for optimisation
} 
Guthuff et al (1997) explained how Value-at-risk (VaR) can be transformed into the Lower partial moment at $n=0^{7}$. In comparing the various different risk measures, Kaplanski and Kroll (2001) noted that VaR is differentiated from Fishburn n-degree risk measures. However, like other below-target-returns risk measures, VaR measure also considers risk as being below a fixed reference point. VaR, in this case, is different from Fishburn's n degree measurement of risk. Fishburn's n degree weighs all the results below a fixed reference point $t$. However, VaR measures risk or the maximum potential loss assuming this loss has a confidence interval of $1-P$. ( $P$ is defined as one of the lower quantiles of the distribution of returns that is only exceeded by a certain percentage like $5 \%, 1 \%$ or $10 \%$ ). Hence, VaR considers risk as one potential loss with a cumulative probability of occurrence of $1-P$, while ignoring both larger and smaller potential losses, involving a target rate. As VaR is a special case of LPM at $n=0$, this restricted the scope of VaR to incorporate degree of risk tolerance of investors as found in the n-degree LPM models. Asset allocation problem can often be solved more effectively if the risk tolerances of investors are accounted for in advance.

However, research in the area of applying LPM models within asset allocation problem is fairly scarce, and especially so about the incorporation of the value of $n$ to highlight the degree of risk tolerance. Nawrocki (1992) is one of the few examples of researches in this area He investigated two topics in relation to the LPM theory: the size and composition of portfolio selected by an n-degree LPM algorithm, and the effect of varying risk tolerance on the performance of investment portfolios.

\footnotetext{
${ }^{7}$ Appendix 1 further illustrates this point.
} 
Nawrocki (1991) described a methodology for modelling co-lower partial moment (CLPM). CLPM incorporates the relationship or interactions of the underlying two assets' lower partial moment. This involves, firstly, the calculation of the semi-deviation (SD) as follows:

$$
S D_{n i}=\left\{\frac{1}{m} \sum_{t=1}^{m}\left[\operatorname{Max}\left(0, h-R_{i t}\right)\right]^{n}\right\}^{1 / n}
$$

where $h$ is the target return, $m$ is the number of observations, $n$ is the LPM degree, which is non-negative and $S D_{n i}$ is the semi deviation for security $i$ for the period $\mathrm{n} . . \mathrm{SD}$ is then involved in the $\mathrm{CLPM}^{8}$ computations as follows:

$$
C L P M=\left(S D_{n i}\right)\left(S D_{n j}\right)\left(r_{i j}\right)
$$

Where $r$ is the correlation coefficient between securities $i$ and $j, S D_{n i}$ and $S D_{n j}$ are the semi deviations for security $i$ and $j$ for the period $\mathrm{n}$.

This paper adopts the methodology for modelling CLPM found in Nawrocki (1991) and Nawrocki (1992). Similar application of the methodology is also found in recent research such as Moreno et al (2005). Section 3 should provide more discussion on the use of methodology for this paper.

\footnotetext{
${ }^{8}$ This approach to compute the CLPM is also known as the Symmetrical CLPM approach. Nawrocki (1991) reported that Elton et al (1978) provide the motivation for using the Symmetrical CLPM. They show that a simple algorithm like this can provide better forecast than a complex optimal algorithm.
} 


\subsection{Data}

The main aim of this paper is to conduct an empirical study using the n-degree

LPM models in the asset allocation problems, similar to Nawrocki (1992). However, we updated the time period of empirical study in this paper, which is from $1999^{9}$ to 2006. We also used a different data-set, now involving the increasingly popular Managed Futures Funds ${ }^{10}$ within an UK equity investment portfolio, which is interesting because research on Managed Futures in a portfolio context is often from the US perspective in the academic literature. Managed Futures often exhibits positive skewness ${ }^{11}$ in the distributional characteristics and this makes the application suitable to the $n$-degree LPM models ${ }^{12}$, which is also quite rare in the literature. We investigate the effect of downside risk on diversification and portfolio returns, by assuming UK investors setting a target return and also change their tolerance for below-target variation within the LPM models.

\footnotetext{
${ }^{9}$ The reason to start from 1999 is because France and Germany begin using euros from 1999. This helps reduce problems on currency conversion

${ }^{10}$ A survey by Eurohedge (see www.eurohedge.com), a trade publication for the European Hedge fund community, shows an annual mid-year (i.e. as at 30th June 2004) total of \$216 billion of assets under management by the European hedge fund community, an increase of over $70 \%$ from $\$ 125$ billion at the end of June 2003 and more than $25 \%$ above the $\$ 168$ billion estimated to have been invested at the start of the year, January 2004. Managed Futures funds are also a subset of the hedge fund industry and the survey provides a breakdown of the $\$ 216$ billion assets under managements, by the type of trading strategies adopted by the hedge funds. The volume of assets under management that were classified as 'Managed Futures' strategies was \$20.3 billion as at July 2004, an increase from the $\$ 12.7$ billion invested as at July 2003 and the $\$ 16.2$ billion invested as at the beginning of January 2004. The Eurohedge research also shows that, out of the $\$ 216$ billion assets under management by the hedge fund community, more than $50 \%$ of the managers are domiciled or based in London. London, therefore, remains, by far the dominant centre for European hedge fund activity, accounting for more than $75 \%$ of the European total assets under management. The huge growth of the Managed Futures industry in Europe over the past years has possibly benefited from the more established, Managed Futures industry in the United States.

${ }^{11}$ All managed futures exhibit positive, but not significant, skewness for the full period, but there is significant positive skewness in some managed futures' returns in the in-sample and out sample. See Table 2.

${ }^{12}$ See footnote 6
} 
Our study used the monthly MSCI stock return data for: the USA, Japan, Germany, France, Switzerland, Canada and the United Kingdom, accessible from DataStream International and are value weighted ${ }^{13}$. We convert returns into UK£ using a one-month forward currency rate ${ }^{14}$. We also include six managed futures indexes or known as the Commodity Trading Advisers (CTAs) indexes, in the UK investor portfolios. These are the Currency CTA, discretionary CTA, diversified CTA, finance CTA, equity CTA and Systematic CTA indexes. The source of data is from CISDM (The Center for International Securities and Derivatives Markets, see cisdm.som.umass.edu). Table 1 describes the strategies used by CTAs. All Managed Futures and MSCI Stock Indexes data are used in the allocations process.

Table $2 \mathrm{~A}, 2 \mathrm{~B}$ and $2 \mathrm{C}$ show the summary statistics for the full period, the in sample and the out sample period. The value of LPM, measures the average monthly below target variations, is computed assuming target rate to be zero percent ${ }^{15}$. Table 2A shows the LPM values are quite similar among the CTA indexes, from about $0.23 \%$ to $0.26 \%$. For the stock indexes, it ranges from as low as $0.08 \%$ to as high as $0.3 \%$. The table also shows most of the stock indexes are negatively skewed, while most CTA indexes are positive skewed. Table $2 \mathrm{~B}$ shows most CTA indexes to have relatively lower LPM ranging from $0.06 \%$ to $0.11 \%$. Among them, the diversified,

\footnotetext{
${ }^{13}$ The countries selected are the same as those in Eun \& Resnick (1988). It is in the currencies of these countries that the UK investors can hedge currency risk via a well-developed forward market.

${ }^{14}$ It is more realistic to report findings in UK£ returns rather than in foreign currency returns since this is from the UK investors' perspectives. This is particularly so for the UK institutional investors, who know more about the UK currency forward contracts. Using the currency forward contracts has the advantage of potentially reducing the variability of assets' returns, which is in the investors' favour. See Eun \& Resnick (1988) for more discussions.

${ }^{15}$ See footnote 6
} 
CTA, Finance CTA and the Systematic CTA indexes are significant positive skewness. However the stock indexes exhibited higher LPM, about $0.18 \%$ to $0.43 \%$.

\section{[Insert Table 1]}

\section{[Insert Table 2]}

\subsection{Methodology}

The effectiveness of the minimum variance model is questionable due to the presence of skewness in the assets' returns showed in table 2 though this is not necessarily for the LPM model ${ }^{16}$. However, the minimum variance portfolio analysis is considered as an appropriate benchmark because of its general use in portfolio theory applications. Therefore, we should include both the minimum variance model and the minimum portfolio LPM models in our analysis and then compared their findings. The following presents the minimum variance portfolio formulations

$$
\operatorname{Minmize} \sum_{i=1}^{n} \sum_{j=1}^{n} \sigma_{i j} x_{i} x_{j}
$$

Subject to:

$$
\begin{aligned}
& \sum^{n} r_{j} x_{j}=\mu \\
& \sum^{n} x_{j}=1 \\
& 0 \leq x_{j} \leq 1, j=1,2, \ldots, n
\end{aligned}
$$

\footnotetext{
${ }^{16}$ See footnote 7
} 
Where $\mu$ is the portfolio expected rate of return, $r_{j}$ is the expected return of security $j, \sigma_{i j}$ is the expected covariance between returns of index $i$ and of index $j$, $x_{j}$ is the proportion invested in asset $j$.

We use the n-degree portfolio LPM algorithm to model the portfolio downside risk presented in Nawrocki (1991) and Moreno et al (2005). The following presents the minimum n-degree portfolio LPM formulations

$$
L P M=\sum_{i=1}^{n} \sum_{j=1}^{n} x_{i} x_{j} C L P M_{i j}
$$

Where,

$$
\begin{array}{ll}
C L P M_{i j}=L P M_{i} & \text { when } i=j \\
C L P M_{i j}=\operatorname{CLPM}_{j i} & \text { when } i \neq j
\end{array}
$$

The investor is assumed to be risk averse about the below target variation and the objective function involved the abovementioned n-degree portfolio LPM. The formulation is as follows:

$$
\text { Minimize } \sum_{i=1}^{n} \sum_{j=1}^{n} x_{i} x_{j} C L P M_{i j}
$$

Subject to:

$$
\begin{aligned}
& \sum^{n} r_{j} x_{j}=\mu \\
& \sum^{n} x_{j}=1 \\
& 0 \leq x_{j} \leq 1, j=1,2, \ldots ., n
\end{aligned}
$$


Where $\mu$ is the portfolio expected rate of return, $r_{j}$ is the expected return of security $j, \sigma_{i j}$ is the expected covariance between returns of index $i$ and of index $j$, $x_{j}$ is the proportion invested in asset $j$.

The minimisation function considers the co lower partial moment (CLPM) ${ }^{17}$. This implied that the lower partial moment for the portfolio is minimised taking into account the relationship of the lower partial moments of the underlying portfolio's assets' returns. The model's allocation is therefore based on assets with the lowest interacted lower partial moment values in the portfolios.

We assumed short selling is prohibited throughout the analysis. The analysis involved optimising the objective functions (8) and (9). For objective function (9), the degree of $\mathrm{n}$, ranging from 1 to 4 , is considered for minimising the portfolio LPM, with $\mathrm{n}=1$ as the most 'tolerance' for below target variation and $\mathrm{n}=4$ as the least 'tolerance'. The weights for the portfolios are derived using the constraints for the respective objective functions. The data inputs are returns in UK£ for all Managed Futures and stock market indexes. This study analyses the performance consequences arising from using these market indexes assets in an UK investment portfolio over 9year period, from 1999 to 2006. The estimation interval is 4 years, from 1999 to 2002. The out of sample testing periods for the optimisation results is from 2003 to 2006 . The holding period is therefore 4 years and the holding period returns are used to compare portfolio returns generated from objective functions (8) and (9).

\footnotetext{
${ }^{17}$ The CLPM takes a symmetrical form as defined in equation (6). See footnote 9.
} 


\section{Discussion of Results}

Table 3, divided into table $3 \mathrm{~A}$ and $3 \mathrm{~B}$, shows the main findings. Table $3 \mathrm{~A}$ shows the asset allocations for the Minimum Variance and the n-degree LPM models (of $n=1$ to $n=4$, denoted as LPM1, LPM2, LPM3 and LPM4), and the underlying individual assets skewness for the in sample period. Table $3 \mathrm{~B}$ shows the portfolio statistics for the out sample, showing the average monthly returns, 4 years holding period returns (thereafter, as HPR) and the skewness for the Minimum Variance and the n-degrees LPM models. Table 4 shows the covariance and the CLPM of the main $\operatorname{assets}^{18}$ allocated in the minimum variance and the various LPM models. We discuss the covariance or the CLPM of these main weighted assets in the allocation models and how this resulted in the portfolio outcomes shown by the out-sample results.

Table $3 \mathrm{~A}$ shows that, the minimum variance model has the highest number of assets allocated. This has the best diversification effects of all the allocation models. The outcome of the allocations (i.e., the out sample results) also show the minimum variance model to produce the least standard deviation when compared to the other LPM models. However, it has also the lowest monthly out sample return of $0.75 \%$. Table 4 shows some values of covariance to be negative, such as those of UK/France stocks and the UK/Germany stocks. These resulted in lower standard deviation, but also lower returns for the portfolio. The allocation of assets in the minimum variance model takes account of the assets' variance and covariance of the entire return distribution. This could potentially bias towards allocating assets that have lower

\footnotetext{
${ }^{18}$ Due to lack of spaces, only assets with relatively higher weightings and making up to more than $50 \%$ of the overall allocations are discussed. These weighted assets and the respective returns they represent, should be sufficient to contribute to the overall portfolio returns. Information on the complete set of variance and covariance
} 
variation on the above-target range of return, and more so, when three of the allocated assets are of significant positive skewness shown in table 3.

\section{[Insert table 3]}

\section{[Insert table 4]}

The LPM models, unlike the minimum variance model, have objective functions that minimises the portfolio LPM. This helps overcome the problem of allocating assets with skewness faced in the minimum variance model. In this model, the returns series of the underlying assets are all transformed ${ }^{19}$ to capture the belowtarget variations of the assets, despite their distributional characteristics, for the purpose of minimising the downside risk of the portfolio. The n-degrees LPM models in table 3 show different degrees of risk tolerance, with $\mathrm{n}=1$ as the most 'tolerance' for below target variation and $n=4$ as the least 'tolerance'. Table 3 shows that the asset allocated falls as the value of $\mathrm{n}$ increases or as the risk tolerance level reduced. It is observed that the average monthly returns and the HPR all decreased following changes to the risk tolerance incorporated in the LPM models. These portfolio returns are affected by the CLPM underlying the portfolios optimized by the n-degrees LPM models. Equivalent to the use of covariance as is the case of the minimum variances model, in the LPM models, CLPM of the various assets' pairs are used instead. This measures the extent of the interactions of the LPM underlying the assets' pairs.

for all assets allocated under the Minimum Variance model, and the CLPM of all the assets allocated underlying the various versions of the LPM portfolios are available on request.

${ }^{19}$ See footnote 7 
Some negative or relatively lower CLPM were observed in table 4. For example, for LPM1, table 4 shows the values of the CLPM of the out samples among the 3 main assets to be $0.0076 \%$ (Canada/France stock), $0.00742 \%$ (Canada/Diversified CTA) and $0.0094 \%$ (France stock/Diversified CTA). These relatively low CLPM are good diversifiers for the below-target variance of the portfolio. The out sample portfolio produced a monthly return of $1.59 \%$. It is notable that as a result of switching from the minimum variance model to the LPM1 model, an increase in skewness occurs (from -0.19 to 0.05 ).

Similar patterns of CLPM are also found in LPM2. They also contribute to minimising the below target variation of the LPM2 portfolios. One of the examples is the value of CLPM associated with the Swiss stock. They are mostly negative except for the Swiss/Germany asset pairs. As $\mathrm{n}$ increases and lesser of risk tolerance is incorporated in the LPM model, it is observed that not only do allocations are reduced, it also becomes more concentrated on one or two of the assets, adversely affecting the diversifications in this case, especially for LPM4.

Table 4 reveals that the German stock is lowly correlated with most assets in the portfolio in terms of the CLPM values and it constitutes $80 \%$ of the portfolio. This limited the contribution to the portfolio outcome positively and resulted in monthly returns of $1.31 \%$, a reduction from $1.37 \%$ (LPM3). The further reductions in the number of assets allocated also resulted in an increase in portfolio skewness to 0.4 . 


\section{$5 \quad$ Concluding Remarks}

The concept of asymmetric risk estimation gained increasing popularity following the use of methodology such as Value-at-risk in risk management. Valueat-risk was discussed in relation to lower partial moment (LPM) in some recent academic literatures, such as Danielsson et al (2006) and Hyung \& de Vries (2005). In this paper, we use the n-degree LPM models, in which we showed analytically Valueat-risk to be a special case, to demonstrate the effect of downside risk reduction on UK portfolio diversification and returns. We investigated the effect by allowing a target threshold return to be set and allowing for the adjustment of risk tolerance for below-target variation or downside risk.

The Minimum Variance model is used alongside with the n-degree LPM models in the portfolio asset allocation process, involving both the Stock Market and the Managed Futures Indexes, due to its general application in portfolio theory. It did not allocate assets as well as it should be, resulting in a lower out sample portfolio returns than the n-degree LPM models. The underlying assets consist of some with significant positive skewed returns and this potentially biased the allocation process since the model minimise the variance underlying the entire distribution of the assets' returns. It is likely assets with good above the target returns are not recognised, especially when skewness was present among some assets. For the n-degree LPM models, all assets' returns are transformed to capture the downside risk before being allocated, despite their distributional characteristics. Skewness does not pose a problem. However, it is observed that the effect of varying the tolerance of downside 
risk in the n-degree LPM models was a reduction in the portfolio returns. This also resulted in the number of assets allocated and the diversification effects to be reduced

To conclude, using the n-degrees LPM models, we presented findings showing that, for investors of a relatively lower level of risk tolerance, the LPM's approach of allocating assets could potentially lead to an increase in skewness to the portfolio that eventually harms both diversification and returns. Findings in Simkowitz \& Beedles (1978) and more recently, for example, Huang \& Yau (2006) also revealed this relationship pattern of skewness and the effect on diversification. More importantly, our finding is also similar to Nawrocki (1992) who used the n-degrees LPM models. This paper has therefore highlighted the importance of proper understanding one's risk tolerance in investment decision making, especially downside risk, which our findings reveal that it could often affect portfolio returns in a negative way.

\section{References}

Bawa, V.S., 1975, Optimal Rules for Ordering Uncertain Prospects, Journal of Financial Economics, 2(1), 95-121

Chunhachinda, P., Dandapani, K., Hamid, S., Prakash, A.J., 1997, Portfolio selection and skewness: Evidence from international stock markets, Journal of Banking and Finance, 21(2), 143-168. 
Danielsson, J., Jorgesen, B. N., Sarma, M., De Vries, C.G (2006), Comparing downside risk measures for heavy tailed distributions, Economic letters, 92, p202208.

Edwards, R., Caglayan, M.O., 2001, Hedge Fund and Commodity Fund Investments in Bull and Bear Markets, Journal of Portfolio Management, Summer, 97-108

Elton, E. J., Gruber, M.J., Urich, T. (1978), Are betas best? Journal of Finance, 33, p1375-1384

Epstein, C.B., (edited), 1992, Managed futures in the institutional portfolio, John Wiley \& Sons, first edition, New York.

Eun, C., Resnick, B., 1988, Exchange Rate Uncertainty, Forward Contracts, and International Portfolio Selection, Journal of Finance, 4, 197 to 215.

Fishburn, P.C., 1977, Mean-Risk Analysis with Risk Associated with Below-Target Returns, American Economic Review, 67(2), 116-126.

Guthoff, A, Pfingsten, A., Wolf, J (1997), On the compatibility of Value-at-risk, other risk concepts and expected utility maximization, in: Hipp, C. et.al. (eds)

Harlow, W.V., 1991, Asset Allocation in a downside risk framework, Financial Analyst Journal, September/October, 28-40. 
Huang C.J., Yau R, 2006, The investor preferences and portfolio selection: is diversification an appropriate strategy? Quantitative Finance, 6(3), p255-271

Hyung, N, De Vries, C.G (2005), Portfolio Diversification effects of Downside risk, Journal of Financial Econometrics, 3(1), p107-125.

Jorion P. (2001), Value-at-Risk: the new Benchmark for Managing Financial Risk. McGraw-Hill: New York

Kaplanski, G, Kroll, Y (2001), VaR Risk Measures versus Traditional Risk Measures: An Analysis and Survey, Journal of Risk, 4(3).

Lai, T.Y., 1991, Portfolio selection with skewness: A multiple-objective approach, Review of Quantitative Finance and Accounting, 1, 293-305.

Markowitz, H., 1959, Portfolio Selection, First Edition, New York: John Wiley \& Sons.

Moreno, D., Marco, P., Olmeda, I (2005), Risk Forecasting models and optimal portfolio selection, Applied Economics, 37, p1267-1281

Nawrocki, D., 1991, Optimal Algorithms and Lower Partial Moment: Ex Post Results, Applied Economics, 23(3), 465-470. 
Nawrocki, D., 1992, The Characteristics of Portfolios Selected by N-Degree Lower

Partial Moment, International Review of Financial Analysis, 1(3), 195-209.

Nawrocki, D., 1999, A brief history of downside risk measures, Journal of Investing, $8,9-25$.

Prakash, A. J., Chang, C.H., Pactwa, T.E., 2003, Selecting a portfolio with skewness: Recent evidence from US, European, and Latin American equity markets, Journal of Banking and Finance, 27(7), 1375-1390.

Scott, R., \& Horvath, P., 1980, In the direction of preference for higher order moments, Journal of Finance, 35, 915-919.

Simkowitz, M.A., Beedles, W.L., 1978, Diversification in a Three Moment World, Journal of Financial and Quantitative Analysis, 13, 927-941. 


\section{partially from Guthoff et al (1997))}

Defining n-degree LPM as:

$$
L P M_{n}(t)=\int_{-\infty}^{t}(t-x)^{n} d f(x)
$$

where $t$ is the target rate of return, $f(x)$ is the probability of getting a return less than $t, x$ is the security returns and " $n$ " is the power or exponential variable that determines the weights investors place on deviations.

If $\mathrm{n}=0$, $\mathrm{n}$-degree LPM derived as follows:

$$
\begin{aligned}
\operatorname{LPM}_{0}(t) & =\int_{-\infty}^{t}(t-x)^{0} d f(x) \\
& =\int_{-\infty}^{t} 1 \cdot f(x) d(x) \\
& =F(t)
\end{aligned}
$$

Therefore, when $\mathrm{n}=0$, i.e., when no weight is placed on the derivation from the target return, $t$, LPM is a cumulative distribution function of normality $(F(t))$.

Setting the target as zero minus the "value" at risk, (i.e., the pre-determined worst expected loss of the security), then we get the following

$$
\begin{array}{lll}
\text { Since } & \quad L P M_{0}(t)=F(t), & \text { from (1) } \\
\text { then } & L P M_{0}(-\operatorname{VaR}(p))=F(-\operatorname{VaR}(p)) &
\end{array}
$$

Equivalent to: $\operatorname{VaR}(p)=-F^{-1}(\operatorname{LPM}(-\operatorname{VaR}(p)))$

Proof: Value at risk is transformed into Lower Partial Moment of zero, $L P M_{0}(-\operatorname{VaR}(p))$, of target $\mathrm{t}$ $=-\operatorname{VaR}(p)$, giving the probability that the actual loss to be greater than $-\operatorname{VaR}(p)$ 
Table 1: Commodity Trading Advisor (CTAs) investment styles and descriptions

Investment Style

Descriptions

\section{Currency CTAs ${ }^{1}$}

\section{Financial CTAs ${ }^{1}$}

\section{Diversified CTAs}

\section{Discretionary $\boldsymbol{C T A s}^{2}$}

\section{Equity CTAs $^{3}$}

\section{Systematic CTAs ${ }^{3}$}

${ }^{1}$ Source: Edwards \& Caglayan, (2001)

${ }^{2}$ Source: Epstein, C.B. (1992), pg 125.

${ }^{3}$ Source: The CISDM Website
Trade futures, forwards and options on currencies. Investors choose a particular CTA with an investment strategy that suits their risk preferences and have their funds managed by that CTA on an individual basis. Investments with CTAs are typically available only to investors with substantial net worth

Trade futures, forwards, and options on fixed-income instruments

Trade futures, forwards, and options on all types of commodities and financial instruments

The discretionary CTA makes trading decisions with the use of human inputs and emotions. This type of manager often uses personal experiences to make and execute trading decisions, but may also use some sort of computer system as well. The key in this case is that the advisor may or may not, with almost equal probability, follow the signals being generated by the 'system'.

The Equity CTAs mainly trade a wide variety of OTC and exchange traded equity futures/options. They tend to rely on a wide variety of trading models.

Systematic CTAs trade a wide variety of OTC and exchange traded forward, futures and options markets. However, they often adopt a predetermined systematic trading model. 


\section{Table 2: Descriptive statistics summary for the Returns of the MSCI and CTA Indexes}

A) Descriptive Statistics for the returns of the MSCI stock and CTA indexes for the full period - 1999 to 2006

\begin{tabular}{|c|c|c|c|c|c|c|c|c|}
\hline MSCI Stock/Managed Futures Indexes & Mean & Max & Min & Std. Dev. & Skew & LPM & Kurtosis & Jarque-Bera (JB) \\
\hline MSCI Canada index & $3.09 \%$ & $25.74 \%$ & $-11.08 \%$ & $8.95 \%$ & 0.3076 & $0.18 \%$ & 2.4493 & 2.7268 \\
\hline MSCI Japan Index & $1.68 \%$ & $32.64 \%$ & $-17.67 \%$ & $10.64 \%$ & $* * * 0.8386$ & $0.30 \%$ & 3.6500 & 12.9409 \\
\hline MSCI Switzerland Index & $1.22 \%$ & $19.37 \%$ & $-17.50 \%$ & $5.86 \%$ & -0.0769 & $0.12 \%$ & 3.5779 & 1.4304 \\
\hline MSCI US Index & $-0.61 \%$ & $15.53 \%$ & $-16.56 \%$ & $7.45 \%$ & 0.0190 & $0.31 \%$ & 2.5919 & 0.6721 \\
\hline MSCI UK Index & $0.17 \%$ & $8.47 \%$ & $-12.77 \%$ & $3.73 \%$ & $* * *-0.9339$ & $0.08 \%$ & 4.4165 & 21.9827 \\
\hline MSCI France Index & $0.76 \%$ & $13.94 \%$ & $-15.20 \%$ & $5.64 \%$ & -0.3734 & $0.15 \%$ & 3.1048 & 2.2749 \\
\hline MSCI Germany Index & $0.62 \%$ & $19.77 \%$ & $-24.23 \%$ & $7.17 \%$ & $*_{-}-0.3990$ & $0.25 \%$ & 4.2095 & 8.3987 \\
\hline Currency CTA & $-0.46 \%$ & $17.00 \%$ & $-14.52 \%$ & $6.70 \%$ & 0.1076 & $0.24 \%$ & 2.5497 & 0.9961 \\
\hline Diversified CTA & $-0.21 \%$ & $22.22 \%$ & $-14.84 \%$ & $7.31 \%$ & 0.3062 & $0.26 \%$ & 3.0528 & 1.5110 \\
\hline Equity CTA & $-0.25 \%$ & $16.04 \%$ & $-13.15 \%$ & $7.28 \%$ & 0.2026 & $0.26 \%$ & 2.2078 & 3.1673 \\
\hline Finance CTA & $-0.04 \%$ & $23.17 \%$ & $-14.87 \%$ & $7.12 \%$ & 0.3682 & $0.23 \%$ & 3.3802 & 2.7467 \\
\hline Discretionary CTA & $0.04 \%$ & $19.45 \%$ & $-13.21 \%$ & $7.28 \%$ & 0.3362 & $0.23 \%$ & 2.6954 & 2.1795 \\
\hline Systematic CTA & $-0.32 \%$ & $22.45 \%$ & $-13.70 \%$ & $6.97 \%$ & 0.3329 & $0.24 \%$ & 3.2413 & 2.0062 \\
\hline
\end{tabular}

Note: 1) The Jarque-Bera (JB) Statistics tests for skewness by taking into account kurtosis. It is estimated as JB $=\mathrm{N}[\mathrm{s} 2 / 6+(\mathrm{k}-3) 2 / 24]$, where $\mathrm{S}$ denotes the value of, skewness and $\mathrm{k}$ denotes the value of kurtosis, $\mathrm{N}$ denotes the number of data used for the test. The JB test follows a chi square distribution with 2 degree of freedom. 2 ) (***) indicates $1 \%$ level significance (critical value for chi square is 9.21 ) and (**) indicates $5 \%$ level significance (critical value for chi square is 5.991 ). 3 ) The return of the index values are all in UK£, converted from foreign currency using the one month currency forward contract. 4) LPM measures the below target variance. It is based on the Formula $\operatorname{LPM}(\mathrm{n}, \mathrm{t})=\frac{1}{k} \sum_{i=1}^{k}\left[\operatorname{Max}\left(0,\left(t-R_{T}\right)\right]^{n} \quad\right.$ Where $\mathrm{K}$ is the number of observations, $\mathrm{t}$ is the target return, $\mathrm{n}$ is the degree of the lower partial moment, RT is the return for the asset during time period T, and Max is a maximisation function which chooses the larger of two numbers, 0 or (t - RT) 
Table 2 (con't) : Descriptive statistics summary for the Returns of the MSCI and CTA Indexes

B) Descriptive Statistics for the returns of the MSCI stock and CTA indexes for the in-Sample period - 1999 to 2002

\begin{tabular}{|c|c|c|c|c|c|c|c|c|}
\hline MSCI Stock/Managed Futures Indexes & Mean & Max & Min & Std. Dev. & Skew & LPM & Kurtosis & Jarque-Bera (JB) \\
\hline MSCI Canada index & $1.52 \%$ & $20.88 \%$ & $-10.70 \%$ & $8.18 \%$ & 0.4465 & $0.20 \%$ & 2.4984 & 2.0977 \\
\hline MSCI Japan Index & $4.20 \%$ & $32.64 \%$ & $-17.67 \%$ & $13.79 \%$ & 0.3063 & $0.43 \%$ & 2.1420 & 2.2227 \\
\hline MSCI Switzerland Index & $0.40 \%$ & $10.57 \%$ & $-17.50 \%$ & $6.07 \%$ & -0.4815 & $0.18 \%$ & 2.9377 & 1.8624 \\
\hline MSCI US Index & $1.59 \%$ & $15.53 \%$ & $-16.56 \%$ & $7.26 \%$ & -0.3158 & $0.20 \%$ & 2.9063 & 0.8152 \\
\hline MSCI UK Index & $-0.81 \%$ & $7.92 \%$ & $-12.77 \%$ & $4.54 \%$ & -0.5628 & $0.15 \%$ & 2.9522 & 2.5389 \\
\hline MSCI France Index & $0.09 \%$ & $13.94 \%$ & $-15.20 \%$ & $6.90 \%$ & -0.1760 & $0.24 \%$ & 2.2989 & 1.2309 \\
\hline MSCI Germany Index & $-0.54 \%$ & $19.77 \%$ & $-24.23 \%$ & $8.60 \%$ & -0.3213 & $0.43 \%$ & 3.1226 & 0.8558 \\
\hline Currency CTA & $2.48 \%$ & $17.00 \%$ & $-8.39 \%$ & $5.61 \%$ & 0.1726 & $0.07 \%$ & 2.9459 & 0.2442 \\
\hline Diversified CTA & $2.97 \%$ & $22.22 \%$ & $-12.11 \%$ & $6.06 \%$ & $* * 0.5472$ & $0.06 \%$ & 4.4674 & 6.7021 \\
\hline Equity CTA & $2.63 \%$ & $14.95 \%$ & $-13.15 \%$ & $6.21 \%$ & -0.3428 & $0.11 \%$ & 2.8284 & 0.9987 \\
\hline Finance CTA & $2.81 \%$ & $23.17 \%$ & $-11.77 \%$ & $6.06 \%$ & $* * * 0.6374$ & $0.07 \%$ & 5.1438 & 12.4428 \\
\hline Discretionary CTA & $3.03 \%$ & $16.62 \%$ & $-9.88 \%$ & $5.59 \%$ & 0.0739 & $0.06 \%$ & 2.9347 & 0.0522 \\
\hline Systematic CTA & $2.64 \%$ & $22.45 \%$ & $-11.16 \%$ & $5.86 \%$ & $* * * 0.6735$ & $0.06 \%$ & 4.9489 & 11.2251 \\
\hline
\end{tabular}

Note: 1) The Jarque-Bera (JB) Statistics tests for skewness by taking into account kurtosis. It is estimated as JB $=\mathrm{N}[\mathrm{s} 2 / 6+(\mathrm{k}-3) 2 / 24]$, where $\mathrm{S}$ denotes the value of, skewness and $\mathrm{k}$ denotes the value of kurtosis, $\mathrm{N}$ denotes the number of data used for the test. The JB test follows a chi square distribution with 2 degree of freedom. 2 ) ( $* * *$ ) indicates $1 \%$ level significance (critical value for chi square is 9.21 ) and (**) indicates $5 \%$ level significance (critical value for chi square is 5.991 ). 3 ) The return of the index values are all in UK£, converted from foreign currency using the one month currency forward contract. 4) LPM measures the below target variance. It is based on the

Formula $\operatorname{LPM}(\mathrm{n}, \mathrm{t})=\frac{1}{k} \sum_{i=1}^{k}\left[\operatorname{Max}\left(0,\left(t-R_{T}\right)\right]^{n} \quad\right.$ Where $\mathrm{K}$ is the number of observations, $\mathrm{t}$ is the target return, $\mathrm{n}$ is the degree of the lower partial moment, RT is the return for the asset during time period T, and Max is a maximisation function which chooses the larger of two numbers, 0 or $(\mathrm{t}-\mathrm{RT})$. 


\section{Table 2 (con't) : Descriptive statistics summary for the Returns of the MSCI and CTA Indexes}

C) Descriptive Statistics for the returns of the MSCI stock and CTA indexes for the out-sample period - 2003 to 2006

\begin{tabular}{|c|c|c|c|c|c|c|c|c|}
\hline MSCI Stock/Managed Futures Indexes & Mean & Max & Min & Std. Dev. & Skew & LPM & Kurtosis & Jarque-Bera (JB) \\
\hline MSCI Canada index & $4.67 \%$ & $25.74 \%$ & $-11.08 \%$ & $9.48 \%$ & 0.1101 & $0.17 \%$ & 2.4087 & 0.7963 \\
\hline MSCI Japan Index & $-0.83 \%$ & $9.85 \%$ & $-11.59 \%$ & $5.10 \%$ & 0.0125 & $0.16 \%$ & 2.5091 & 0.4833 \\
\hline MSCI Switzerland Index & $2.04 \%$ & $19.37 \%$ & $-10.25 \%$ & $5.59 \%$ & 0.5141 & $0.07 \%$ & 3.7984 & 3.3895 \\
\hline MSCI US Index & $-2.81 \%$ & $14.81 \%$ & $-15.84 \%$ & $7.05 \%$ & 0.3334 & $0.42 \%$ & 2.9540 & 0.8937 \\
\hline MSCI UK Index & $1.15 \%$ & $8.47 \%$ & $-5.25 \%$ & $2.35 \%$ & -0.0608 & $0.01 \%$ & 4.1773 & 2.8018 \\
\hline MSCI France Index & $1.42 \%$ & $11.55 \%$ & $-9.52 \%$ & $3.98 \%$ & -0.2266 & $0.05 \%$ & 3.6870 & 1.3548 \\
\hline MSCI Germany Index & $1.78 \%$ & $18.41 \%$ & $-11.49 \%$ & $5.23 \%$ & $* * 0.4785$ & $0.07 \%$ & 4.8079 & 8.3688 \\
\hline Currency CTA & $-3.40 \%$ & $11.82 \%$ & $-14.52 \%$ & $6.45 \%$ & 0.4664 & $0.42 \%$ & 2.7009 & 1.9194 \\
\hline Diversified CTA & $-3.38 \%$ & $13.94 \%$ & $-14.84 \%$ & $7.11 \%$ & 0.7063 & $0.45 \%$ & 3.0629 & 3.9987 \\
\hline Equity CTA & $-3.13 \%$ & $16.04 \%$ & $-12.68 \%$ & $7.17 \%$ & $* * 0.9567$ & $0.41 \%$ & 3.3123 & 7.5167 \\
\hline Finance CTA & $-2.90 \%$ & $14.74 \%$ & $-14.87 \%$ & $7.01 \%$ & 0.6833 & $0.40 \%$ & 3.0934 & 3.7529 \\
\hline Discretionary CTA & $-2.94 \%$ & $19.45 \%$ & $-13.21 \%$ & $7.60 \%$ & $* * * 1.1173$ & $0.41 \%$ & 4.0014 & 11.9920 \\
\hline Systematic CTA & $-3.27 \%$ & $12.57 \%$ & $-13.70 \%$ & $6.78 \%$ & 0.6349 & $0.42 \%$ & 2.8715 & 3.2582 \\
\hline
\end{tabular}

Note: 1) The Jarque-Bera (JB) Statistics tests for skewness by taking into account kurtosis. It is estimated as JB=N[s2/6+(k-3)2/24], where $\mathrm{S}$ denotes the value of, skewness and $\mathrm{k}$ denotes the value of kurtosis, $\mathrm{N}$ denotes the number of data used for the test. The JB test follows a chi square distribution with 2 degree of freedom. 2 ) ( $* * *)$ indicates $1 \%$ level significance (critical value for chi square is 9.21 ) and (**) indicates $5 \%$ level significance (critical value for chi square is 5.991 ). 3 ) The return of the index values are all in UK£, converted from foreign currency using the one month currency forward contract. 4) LPM measures the below target variance. It is based on the Formula $\operatorname{LPM}(\mathrm{n}, \mathrm{t})=\frac{1}{k} \sum_{i=1}^{k}\left[\operatorname{Max}\left(0,\left(t-R_{T}\right)\right]^{n} \quad\right.$ Where $\mathrm{K}$ is the number of observations, $\mathrm{t}$ is the target return, $\mathrm{n}$ is the degree of the lower partial moment, RT is the return for the asset during time period T, and Max is a maximisation function which chooses the larger of two numbers, 0 or $(\mathrm{t}-\mathrm{RT})$. 
Table 3 : Portfolio Allocations and the Out-Sample Portfolio Results of Minimum Variance and Minimum LPM (estimating using 48 monthly returns from 1999 to 2002) for the MSCI stock market and CTA indexes

A) Portfolio Assets Allocations

\begin{tabular}{|c|c|c|c|c|c|c|}
\hline Portfolio Assets & $\begin{array}{l}\text { Assets in sample } \\
\text { Skewness }\end{array}$ & MV & $\begin{array}{l}\text { LPM } \\
(\mathbf{n}=\mathbf{1}) \\
\end{array}$ & $\begin{array}{l}\text { LPM } \\
(\mathbf{n}=\mathbf{2}) \\
\end{array}$ & $\begin{array}{l}\text { LPM } \\
(\mathbf{n}=\mathbf{3}) \\
\end{array}$ & $\begin{array}{r}\text { LPM } \\
(\mathbf{n}=4) \\
\end{array}$ \\
\hline MSCI Canada index & 0.4465 & $9 \%$ & $40 \%$ & $8 \%$ & $7 \%$ & $0 \%$ \\
\hline $\begin{array}{l}\text { MSCI Japan Index } \\
\text { MSCI Switzerland }\end{array}$ & 0.3063 & $0 \%$ & $2 \%$ & $0 \%$ & $5 \%$ & $7 \%$ \\
\hline Index & -0.4815 & $25 \%$ & $8 \%$ & $19 \%$ & $19 \%$ & $2 \%$ \\
\hline MSCI US Index & -0.3158 & $6 \%$ & $0 \%$ & $5 \%$ & $0 \%$ & $0 \%$ \\
\hline MSCI UK Index & -0.5628 & $13 \%$ & $4 \%$ & $32 \%$ & $31 \%$ & $6 \%$ \\
\hline MSCI France Index & -0.1760 & $16 \%$ & $20 \%$ & $18 \%$ & $17 \%$ & $0 \%$ \\
\hline MSCI Germany Index & -0.3213 & $12 \%$ & $1 \%$ & $16 \%$ & $15 \%$ & $80 \%$ \\
\hline Currency CTA & 0.1726 & $3 \%$ & $0 \%$ & $1 \%$ & $0 \%$ & $0 \%$ \\
\hline Diversified CTA & $* * 0.5472$ & $3 \%$ & $13 \%$ & $0 \%$ & $0 \%$ & $5 \%$ \\
\hline Equity CTA & -0.3428 & $4 \%$ & $2 \%$ & $0 \%$ & $0 \%$ & $0 \%$ \\
\hline Finance CTA & $* * * 0.6374$ & $4 \%$ & $4 \%$ & $1 \%$ & $5 \%$ & $0 \%$ \\
\hline Discretionary CTA & 0.0739 & $1 \%$ & $1 \%$ & $0 \%$ & $0 \%$ & $0 \%$ \\
\hline Systematic CTA & $* * * 0.6735$ & $4 \%$ & $3 \%$ & $0 \%$ & $0 \%$ & $0 \%$ \\
\hline Total allocation & & $100 \%$ & $100 \%$ & $100 \%$ & $100 \%$ & $100 \%$ \\
\hline $\begin{array}{l}\text { Number of assets } \\
\text { Allocated }\end{array}$ & & 12 & 11 & 8 & 7 & 5 \\
\hline
\end{tabular}

\section{B) Portfolio Statistics}

\section{Out-Sample Results}

Average monthly returns

4 years (2003 to 2006)

holding periods returns

Standard Deviation

Skewness

$\begin{array}{ccccc}\text { MV } & \text { LPM 1 } & \text { LPM 2 } & \text { LPM 3 } & \text { LPM 4 } \\ 0.75 \% & * 1.59 \% & * * * 1.44 \% & * * * 1.37 \% & * * 1.31 \% \\ 38.35 \% & 97.76 \% & 94.72 \% & 88.86 \% & 78.59 \% \\ & & & & \\ 4.20 \% & 5.03 \% & 4.84 \% & 4.70 \% & 7.50 \% \\ -0.19 & 0.05 & 0.12 & 0.19 & * 0.40\end{array}$

Note:

1) The critical values for testing the differences of the portfolio returns among the various allocation methods (i.e., $L P M$ of $n=1, n=2$, $n=3, n=4$ and the $M V$ ) are 2.43 (5\% significant level), 3.45 (1\% significant level). As the F critical value ( $p$ value) is about 1.428 (0.000) ,the null hypothesis of no difference among the monthly returns series generated by the various allocation methods can therefore be rejected. These portfolios returns are therefore significantly different from one another. Our results are similar to that in Nawrocki (1992), which show that portfolio out sample returns do also decrease, from 2.514 to 2.4849, as the LPM is adjusted from $n=1$ to $n=4$.

2) (***) indicates 1\% level significance (critical value for chi square is 9.21), (**) indicates 5\% level significance (critical value for chi square is 5.991) and (*) indicates 10\% level significance (critical value for chi square). The estimation of skewness is based on the Jarque-Bera statistics test . 
Table 4: Analysis of Covariance and CLPM underlying the assets in the models

\begin{tabular}{|c|c|c|}
\hline \multicolumn{3}{|c|}{ Minimum Variance } \\
\hline \multicolumn{3}{|c|}{ Assets allocated (weighting) } \\
\hline \multicolumn{3}{|c|}{ Switzerland stock (25\%), UK stock (13\%), France stock (16\%), Germany stock (12\%) } \\
\hline Assets' pairs & In sample covariance & Out sample covariance \\
\hline Swiss/UK Stock & 0.1363 & 0.0165 \\
\hline Swiss/France stock & 0.0620 & 0.0978 \\
\hline Swiss/Germany stock & 0.0876 & 0.1555 \\
\hline UK/France Stock & 0.2352 & -0.0175 \\
\hline UK/Germany Stock & 0.2868 & -0.0115 \\
\hline France/Germany Stock & 0.5570 & 0.1948 \\
\hline
\end{tabular}

\section{LPM1}

Assets allocated (weighting)

Canada stock (40\%); France stock (20\%); Diversified CTA (13\%)

\section{Assets' pairs}

Canada/France stock

Canada/Diversified CTA

France stock/Diversified CTA $\underline{\text { In sample CLPM }}$

0.0505
0.0075
0.0003

\section{Out sample CLPM}

0.0076

0.0742

0.0094

\section{$\underline{\text { LPM2 }}$}

\section{Assets allocated (weighting)}

Switzerland stock (19\%), UK stock (32\%); France stock (18\%), Germany (16\%)

\section{Assets' pairs}

Swiss/UK Stock

Swiss/France Stock

Swiss/Germany stock

UK/France Stock

UK/Germany stock

France/Germany Stock

\section{In sample CLPM}

0.0737

$-0.0071$

$-0.0016$

0.1419

0.1934

0.3022

\section{Out sample CLPM}

$-0.0016$

$-0.0017$

0.0024

$-0.0015$

$-0.0018$

0.0576

Note: 1) Only assets with proportions of more than 50\% in total are discussed in this table. See table 3 for full lists of assets allocated. 2) CLPM is calculated as $C L P M=\left(S D_{n i}\right)\left(S D_{n j}\right)\left(r_{i j}\right)$ where $\mathrm{r}$ is the correlation coefficient between securities i and $\mathrm{j}, S D_{n i}$ and $S D_{n j}$ are the semi deviations for security $\mathrm{i}$ and $\mathrm{j}$ for the period $\mathrm{n}$. The semi deviation is calculated as $S D_{n i}=\left\{\frac{1}{m} \sum_{t=1}^{m}\left[\operatorname{Max}\left(0, h-R_{i t}\right)\right]^{n}\right\}^{1 / n}$ where $\mathrm{h}$ is the target return, $\mathrm{m}$ is the is the number of observations and $\mathrm{n}$ is the LPM degree 
Table 4 (con't) : Analysis of Covariance and CLPM underlying the assets in the models

\section{LPM3}

\section{Assets allocated (weighting)}

Switzerland stock (19\%), UK stock (31\%), France stock (17\%), Germany stock (15\%)

\section{Assets' pairs}

Swiss/UK Stock

Swiss/France Stock

Swiss/Germany stock

UK/France Stock

UK/Germany stock

France/Germany Stock
In sample CLPM

0.1187

$-0.0189$

$-0.0139$

0.2516

0.3632

0.5128

\section{Out sample CLPM}

$-0.0029$

$-0.0055$

$-0.0025$

$-0.0025$

$-0.0027$

0.1203

\section{LPM4}

Assets allocated (weighting)

Japan Stock (7\%), Switzerland stock (2\%), UK stock (6\%),

Germany stock (80\%), Diversified CTA (5\%)

Assets' pairs
Japan/Swiss Stock
Japan/UK Stock
Japan/Germany Stock
Japan/Diversified CTA
Swiss/UK Stock
Swiss/Germany Stock
Swiss/Diversified
UK/Germany stock
UK/Diversified CTA
Germany/Diversified CTA

\section{In sample CLPM}

$-0.0492$

0.0088

0.0363

0.0786

0.1502

$-0.0228$

$-0.0123$

0.5474

$-0.0137$

$-0.0161$

\begin{tabular}{c} 
Out sample CLPM \\
\hline 0.0066 \\
-0.0067 \\
0.0077 \\
0.0494 \\
-0.0035 \\
-0.0062 \\
0.1659 \\
-0.0034 \\
-0.0139 \\
0.0183
\end{tabular}

Note: 1) Only assets with proportions of more than 50\% in total are discussed in this table. See table 3 for full lists of assets allocated. 2) CLPM is calculated as $C L P M=\left(S D_{n i}\right)\left(S D_{n j}\right)\left(r_{i j}\right)$ where $\mathrm{r}$ is the correlation coefficient between securities $\mathrm{i}$ and $\mathrm{j}, S D_{n i}$ and $S D_{n j}$ are the semi deviations for security $\mathrm{i}$ and $\mathrm{j}$ for the period $\mathrm{n}$. The semi deviation is calculated as $S D_{n i}=\left\{\frac{1}{m} \sum_{t=1}^{m}\left[\operatorname{Max}\left(0, h-R_{i t}\right)\right]^{n}\right\}^{1 / n}$ where $\mathrm{h}$ is the target return, $\mathrm{m}$ is the is the number of observations and $\mathrm{n}$ is the LPM degree 